\title{
Complex Matrix Model for Data and Knowledge Representation for Road-Climatic Zoning of the Territories and the Results of Its Approbation
}

\author{
A. Yankovskaya ${ }^{1,2,3,4}$, A. Sukhorukov ${ }^{2}$ \\ ${ }^{I}$ Tomsk State University of Architecture and Building, 634003, Tomsk, Russia \\ ${ }^{2}$ National Research Tomsk State University, 634050, Tomsk, Russia \\ ${ }^{3}$ National Research Tomsk Polytechnic University, 634050, Tomsk, Russia \\ ${ }^{4}$ Tomsk State University of Control Systems and Radioelectronics, 634050, Tomsk, Russia
}

\begin{abstract}
Complex matrix model of data and knowledge representation is proposed for solution of a road-climatic zoning of the territories problem using an intelligent system. This model consists of: 1) an extended matrix model, which includes extended description and distinguishing matrices (the extension is realized by the way of including of additional columns into the description matrix) for the territories under investigation, 2) description and distinguishing matrices of highly qualified experts' knowledge and 3) a partial matrix model, consisting of an extended description matrix of the territories under investigation (recognition). For the first time original approbation results of intelligent data and knowledge analysis on the base of intelligent instrumental software IMSLOG are given. The system is designed and developed in intelligent systems laboratory of the Tomsk State University of Architecture and Building to solve the problem of road-climatic zoning.
\end{abstract}

Keywords: complex matrix model; intelligent data analysis; approbation results; geocomplex, road-climatic zoning

\section{Introduction}

An urgent need in intelligent systems (IS) application for a number of problem areas is not in doubt. Among the basic IS applications are those given in the monograph [1]: medicine, engineering, transport system and others. Among the fundamental IS components we distinguish the data and knowledge base. In this paper we will concentrate our efforts on the base construction.

When developing the design standards for the highways we should take into account the regional features of the geographic territories. It is performed through the method of road-climatic zoning. The method serves as a basis for the development of building regulations, directives and guidelines valid in Russia [2,3], China [4,5], USA [6], Germany [7], Great Britain, Sweden [8] and in other countries, including such neighboring countries as Kazakhstan [9], Belorussia [10], Kyrgyzstan [11]. According to the building regulations [2,3] the Russian Federation territory is zone differentiated and divided into 5 roadclimatic zones, which are differing sufficiently in terms of the complexes of nature-climatic and geoengineering conditions. In their turn, the zones are divided into 9 subzones due to the road industry standards [9] and into 13 subzones due to the set of rules [3]. Depending on the position of the road section under design in one or another zone and subzone the road designers make technical decisions, providing safe and convenient traffic according to the requirement stated in [2,3].

A number of researchers in their papers [12-15] point out that the existing special position of the zones and subzones boundaries does not allow to provide the level of operational reliability of the highways due to the operability criterion since the position of the zones and subzones are not substantiated sufficiently. This situation is especially inherent to Western Siberia and Far East. That leads to an increase in financial and labor resources for maintaining and restoring the required technical condition of highways. Thus the research of the new approaches to the road-climatic zoning design is rather actually. The specificity of data and knowledge to solve the problem of the road-climatic zoning requires the new methods of the data and knowledge representation. Taking into consideration is proposed to choose intelligent instrumental software IMSLOG (IIS IMSLOG) $[16,17]$ for IS construction of road-climatic zoning of territories (IS RCZT).

Hereafter we give a description of a complex matrix model for the data and knowledge representation for the IS RCZT. The IS RCZT is based on test methods of pattern recognition and cognitive graphics tools.

\section{Complex Matrix Model for Data and Knowledge Representation}

For the first time we suggest to represent the complex model by 3 types of the following matrix models of data and knowledge representation [18,19]:

1. An extended matrix model including an extended matrix of descriptions and a matrix of distinguishing. The extension is performed due to additional columns introduction to the matrix of descriptions [19]. The matrix of descriptions sets the objects description within the space of characteristic features. The additional columns correspond to compulsory features: zones, subzones, road districts, supporting point of the investigated territories. The present paper deals with the research results on Western Siberia territory. The columns of the extended matrix of descriptions correspond to characteristic features, represented by the 3 groups of factors. Those factors constitute the geographical complex of the territory: zonal, intrazonal and regional factors. The columns of the matrix of distinguishing correspond to the zones, subzones and road districts. We use integer features in the model. 
Image Processing, Geoinformation Technology and Information Security / A. Yankovskaya, A. Sukhorukov

2. A matrix of expert knowledge description without compulsory features and a matrix of distinguishing. The columns of the matrix of distinguishing, as well as those of the matrix of distinguishing of the extended matrix model, correspond to the zones, subzones and road districts. Here we also use integer features.

3. A partial matrix model, consisting only of the extended matrix of description of the investigated territories under recognition.

Now we concentrate on the elements description of the matrices under consideration. The integer values of the characteristic features including grouped ones and the compulsory features are the elements of the extended matrix of objects' description $\left(\mathrm{Q}^{\mathrm{e}}\right)$. The group characteristic features are split into the features of the integer values, which correspond to a certain partition intervals of the feature under study. A column of the matrix $Q^{e}$ corresponds to each characteristic features. A row of the matrix $\mathrm{Q}^{\mathrm{e}}$ corresponds to the stronghold for which the values of characteristic features are determined. Thus, the element of the matrix $\mathrm{Q}^{\mathrm{e}}$ is the value of the integer characteristic features, including compulsory one. This feature correspond to a certain supporting point [18]. Note that the compulsory features are not used in regulations revealing. They are implemented only for the mapping of the zones, subzones and road districts.

Integer values of the classification features of three types are the elements of the matrix of distinguishing $\left(\mathrm{R}^{\mathrm{e}}\right)$. We restrict our study to the diagnostic matrix of distinguishing. For the matrix under study each subsequent column splits the previous one into the classes of equivalency. Due to the methodology given in [20,21], we will use the three classification features of diagnostic type. The 1 st feature corresponds to the zones, the 2 nd one - to the subzones, the 3rd one - to the road districts.

We note that we need the 2nd matrix model due to the incomplete information on the zones, subzones and road districts. Such information is contained in the 1st matrix model. The rows of the matrix of description and the matrix of distinguishing are fulfilled by the highly qualified experts in the problem area. Matrix fulfillment with data is performed by the colleagues of the Automobile roads building department of the Tomsk State University of Architecture and Building.

The learning sample is represented by the extended matrix model. In the learning sample some combinations of the classification features could not be represented. Therefore, the dimensions of the matrix of description and the matrix of distinguishing could exceeded sufficiently the dimensions of the matrix of the extended matrix model, fulfilled beforehand. This is due to the absence of a number of combinations of the classification features values in the learning sample.

The extended matrix of description of the territories under recognition for the partial matrix model is fulfilled by the highly qualified experts. They use the reference data and the data acquired during field and/or laboratory research. The research results could be transmitted both to the system's users and to the enterprises, interested in the road-climatic zoning research results.

The decision making about the supporting point correspondence to a certain zone, subzone and road district we perform using the two aforementioned matrix representations (extended matrix and the one based on the expert knowledge) based on the rules of the total decision making with use of IS RCZT. The architecture IS RCZT is presented in the publication [22].

\section{Data and knowledge structuring. Bases of a database and knowledge construction}

The basis of the information technology of road-climatic zoning of territories is IS RCZT. To create the IS we united our efforts with our colleagues. Together with specialists in the cognitive science and experts in road-climatic zoning we have structured the data and knowledge on road-climatic zoning. The structuring has been performed based on the complex matrix model of data and knowledge representation, described in section 2.

A list of characteristic features with indicating their values for the matrices of description is given in Table 1. The characteristic features are grouped ones beginning with characteristic features $z_{10}$. Symbolic characteristic features, intervals of the integer characteristic features partitions as well as the real characteristic features are coded by numbers. The number 20 (limiter) is used only for the sake of size reduction of the data and knowledge matrix representation. In table 1 , the value of an integer feature is not greater than 8 .

Table 1. A list of characteristic features excluding compulsory ones

\begin{tabular}{|c|c|c|}
\hline Characteristic feature & Code & Intervals of values \\
\hline Vegetation type & $\mathrm{z}_{1}$ & $\begin{array}{l}1 \text { - tundra vegetation; } 2 \text { - forest-tundra vegetation; } 3 \text { - forest vegetation (northern taiga, with } \\
\text { propagation of permafrost soils); } 4 \text { - forest vegetation (middle taiga); } 5 \text { - forest vegetation (southern } \\
\text { taiga); } 6 \text { - forest-steppe vegetation; } 7 \text { - steppe vegetation; } 8 \text { - desert and desert steppe vegetation }\end{array}$ \\
\hline Terrain relief & $\mathrm{z}_{2}$ & $\begin{array}{l}1 \text { - flat terrain with a relative elevation of the relief (RER) up to } 25 \mathrm{~m} ; 2 \text { - hilly with RER from } 25 \mathrm{~m} \\
\text { up to } 200 \mathrm{~m} ; 3 \text { - mountainous (low mountains terrain) with RER from } 200 \mathrm{~m} \text { up to } 500 \mathrm{~m} \text {, and with a } \\
\text { prevailing slope gradient (PSG) from } 5^{\circ} \text { up to } 10^{\circ} ; 4-\text { mountainous (mid-mountain terrain) with RER } \\
\text { from } 500 \mathrm{~m} \text { up to } 1000 \mathrm{~m} \text {, PSG from } 10^{\circ} \text { up to } 25^{\circ} \text {, and elevation above sea level of about } 1000-2000 \\
\text { m; } 5 \text { - mountainous (highland terrain) with RER from } 1000 \mathrm{~m} \text {, PSG more than } 25^{\circ} \text {, and elevation } \\
\text { above the sea level more than } 2000 \mathrm{~m}\end{array}$ \\
\hline $\begin{array}{l}\text { Calculated soil } \\
\text { moisture (CSM), p.u. }\end{array}$ & $\mathrm{Z}_{3}$ & $\begin{array}{l}1 \text { - low soil moisture with CSM up to } 0.4 ; 2 \text { - normal soil moisture with CSM from } 0.4 \text {, up to } 0.6 ; 3- \\
\text { increased soil moisture with CSM from } 0.6 \text {, up to } 0.8 ; 4 \text { - waterlogged soil with CSM from } 0.8 \text {, up to } 1\end{array}$ \\
\hline $\begin{array}{l}\text { Evaporation from the } \\
\text { land surface, } \mathrm{mm} / \text { year }\end{array}$ & $\mathrm{z}_{4}$ & $\begin{array}{l}1 \text { - extremely low, from } 100 \mathrm{~mm} \text { up to } 150 \mathrm{~mm} \text { (arctic deserts); } 2 \text {-very low, from } 150 \mathrm{~mm} \text { up to } 200 \\
\mathrm{~mm} \text { (Siberian tundra provinces); } 3 \text { - low, from } 200 \mathrm{~mm} \text { up to } 400 \mathrm{~mm} ; 4 \text { - average, from } 400 \mathrm{~mm} \text { up to } \\
600 \mathrm{~mm} \text { (taiga, central and central black earth regions of Russia, Krasnodar region); } 5 \text { - increased, from } \\
600 \mathrm{~mm} \text { up to } 700 \mathrm{~mm} \text { (mixed forests); } 6 \text { - high evaporation, from } 700 \mathrm{~mm} \text { up to } 800 \mathrm{~mm} ; 7 \text { - very } \\
\text { high evaporation, from } 800 \mathrm{~mm} \text { up to } 900 \mathrm{~mm} \text { (steppers); } 8 \text { - extremely high, from } 900 \mathrm{~mm} \text { up to } 1000 \\
\mathrm{~mm} \text { (semi-deserts and deserts) }\end{array}$ \\
\hline
\end{tabular}


Continuation table 1 .

\begin{tabular}{|c|c|c|}
\hline Characteristic feature & Code & Intervals of values \\
\hline $\begin{array}{l}\text { Syelyaninov's } \\
\text { hydrothermic } \\
\text { coefficient }\end{array}$ & $\mathrm{Z}_{5}$ & $\begin{array}{l}1 \text { - redundant moistening of the soil with SHC from } 1,4 \text { to } 5 ; 2 \text { - significant moistening of the soil in } \\
\text { particular years with SHC from } 1 \text { to } 1,4 ; 3 \text { - insufficient moistening of the soil with SHC from } 0,5 \text { to } 1 \text {; } \\
4 \text { - dry regions with SHC up to } 0.5\end{array}$ \\
\hline $\begin{array}{l}\text { A number of days with } \\
\text { negative air } \\
\text { temperature }\end{array}$ & $\mathrm{z}_{6}$ & 1 - low from 141 to $198 ; 2$ - medium from 199 to $246 ; 3$ - high from 247 to 315 \\
\hline $\begin{array}{l}\text { Snow cover height } \\
(\mathrm{SCH}), \mathrm{mm}\end{array}$ & $\mathrm{z}_{7}$ & $\begin{array}{l}1 \text { - snowless regions with SCH up to } 300 ; 2-\text { little snow cover regions with } \mathrm{SCH} \text { from } 300 \text { to } 500 ; 3- \\
\text { medium snow cover regions with SCH from } 500 \text { to } 700 ; 4 \text { - high snow cover regions with SCH from } \\
700 \text { to } 1000 ; 5 \text { - exclusive high snow cover regions with SCH from } 1000 \text { to } 2900\end{array}$ \\
\hline $\begin{array}{l}\text { Soil frost depth (SFD), } \\
\mathrm{cm}\end{array}$ & $\mathrm{Z}_{8}$ & $\begin{array}{l}1 \text { - small frost depth with SFD from } 50 \text { to } 180 ; 2 \text { - medium frost depth with SFD from } 180 \text { to } 220 ; 3- \\
\text { high frost depth with SFD from } 220 \text { to } 260 ; 4 \text { - very high frost depth with SFD from } 260 \text { to } 300 \text {; } \\
\text { excessive frost depth with SFD from } 300 \text { to } 600\end{array}$ \\
\hline $\begin{array}{l}\text { Soil type according to } \\
\text { natural condition I zone }\end{array}$ & $\mathrm{Z}_{9}$ & $\begin{array}{l}1 \text { - continuous distribution of the frozen soils for many years; } 2 \text { - continuous in general of the frozen } \\
\text { soils for many years; } 3 \text { - predominately island distribution of the frozen soils for many years }\end{array}$ \\
\hline $\begin{array}{l}\text { Average air } \\
\text { temperature for many } \\
\text { years, }{ }^{\circ} \mathrm{C}\end{array}$ & $\mathrm{z}_{10}$ & $\begin{array}{l}1 \text { - extremely low temperature with AAT from }-15.5 \text { to }-10.0 ; 2 \text { - very low temperature with AAT } \\
\text { from }-10.0 \text { to }-6.0 ; 3 \text { - low temperature with AAT from }-6.0 \text { to }-2.0 ; 4 \text { - medium temperature with } \\
\text { AAT from }-2.0 \text { to } 2.0 ; 5 \text { - high temperature with AAT from } 2.0 \text { to } 6.0 ; 6 \text { - very high temperature with } \\
\text { AAT from } 6.0 \text { to } 10.0 ; 7 \text { - extremely high temperature with AAT from } 10.0 \text { to } 14.2\end{array}$ \\
\hline $\begin{array}{l}\text { Average minimum air } \\
\text { temperature, }{ }^{\circ} \mathrm{C}\end{array}$ & $\mathrm{z}_{11}$ & $\begin{array}{l}1 \text { - extremely low temperature less than }-40.0 ; 2-\text { very low temperature from }-39.9 \text { to }-32.0 ; 3-\text { low } \\
\text { temperature from }-31.9 \text { to }-24.0 ; 4-\text { medium temperature from }-23.9 \text { to }-16.0 ; 5 \text { - high temperature } \\
\text { from }-15.9 \text { to }-8.0 ; 6 \text { - very high temperature from }-7.9 \text { to } 0.0 ; 7 \text { - extremely high temperature above } 0.0\end{array}$ \\
\hline $\begin{array}{l}\text { Average annual } \\
\text { maximum air } \\
\text { temperature, }{ }^{\circ} \mathrm{C}\end{array}$ & $\mathrm{z}_{12}$ & $\begin{array}{l}1 \text { - extremely low temperature from } 0 \text { to } 4 ; 2 \text { - very low temperature from } 4 \text { to } 7 ; 3 \text { - low temperature } \\
\text { from } 8 \text { to } 11 ; 4 \text { - medium temperature from } 12 \text { to } 15 ; 5 \text { - high temperature from }-16 \text { to } 19 ; 6 \text { - very } \\
\text { high temperature from } 20 \text { to } 23 ; 7 \text { - extremely high temperature above } 24\end{array}$ \\
\hline $\begin{array}{l}\text { Annual precipitation, } \\
\mathrm{mm}\end{array}$ & $\mathrm{Z}_{13}$ & $\begin{array}{l}1 \text { - low less than } 250 ; 2 \text { - medium from } 251 \text { to } 500 ; 3 \text { - high from } 501 \text { to } 1000 ; 4 \text { - very high above } \\
1000\end{array}$ \\
\hline $\begin{array}{l}\text { Annual precipitation } \\
\text { for the cold season, } \mathrm{mm}\end{array}$ & $\mathrm{z}_{14}$ & 1 - low less than $60 ; 2$ - medium from 61 to $150 ; 3$ - high from 151 to $405 ; 4$ - very high above 405 \\
\hline $\begin{array}{l}\text { Annual precipitation } \\
\text { for the warm season, } \\
\mathrm{mm}\end{array}$ & $\mathrm{Z}_{15}$ & 1 - low less than $190 ; 2$ - medium from 191 to $340 ; 3$ - high from 341 to $600 ; 4$ - very high above 600 \\
\hline $\begin{array}{l}\text { Soil humidity on the } \\
\text { liquid limit, p.u. }\end{array}$ & $\mathrm{z}_{16}$ & 1 - low from 0.29 to $0.33 ; 2$ - medium from 0.34 to $0.38 ; 3$ - high from 0.39 to 0.43 \\
\hline $\begin{array}{l}\text { Soil humidity on the } \\
\text { plastic limit, p.u. }\end{array}$ & $\mathrm{z}_{17}$ & 1 - low from 0.20 to $0.23 ; 2$ - medium from 0.24 to $0.26 ; 3$ - high from 0.27 to 0.30 \\
\hline Plasticity index, $\%$ & $\mathrm{z}_{18}$ & $\begin{array}{l}1 \text { - non-cohesive soil (sand, etc.) from } 0 \text { to } 1 ; 2 \text { - clay sand from } 1 \text { to } 7 ; 3 \text { - light clay loam from } 7 \text { to } \\
12 ; 4 \text { - heavy clay loam from } 12 \text { to } 17 ; 5 \text { - light clay from } 17 \text { to } 27 ; 6 \text { - heavy clay from } 27 \text { and above }\end{array}$ \\
\hline Grain-size composition & $\mathrm{z}_{19}$ & 1 - clay sand above $50 ; 2$ - pulverescent clay sand less than 50 \\
\hline
\end{tabular}

of the clay sands, sand grain content, mass $\%$

Grain-size composition of the clay sands, sand grain content, mass \%

Grain-size composition of the clay sands, clay grain content, mass \%

Grain-size composition of the clay loams, sand grain content, mass\%

Grain-size composition of the clay loams, pulverescent grains content, mass \%

Grain-size composition of the clay loams, clay grains content, mass \% Grain-size composition of the clays, sand grain content, mass $\%$

1 - low from 70.540 to $73.279 ; 2$ - medium from 73.280 to $76.019 ; 3$ - high from 76.020 to 78.76

$\mathrm{Z}_{21} \quad 1$ - low from 7.120 to $9.150 ; 2$ - medium from 8.160 to $11.199 ; 3$ - high from 11.200 to 13.240

$\mathrm{Z}_{22} \quad 1$ - sandy clay loam over $40 ; 2$ - pulverescent clay loam less than 50

$\mathrm{z}_{23} \quad 1$ - low from 72.310 to $75.589 ; 2$ - medium from 77.489 to $75.590 ; 3$ - high from 77.490 to 77.540

$\mathrm{Z}_{24} \quad 1$ - low from 18.400 to $18.455 ; 2$ - medium from 18.456 to $20.510 ; 3$ - high from 20.511 to 23.870

z25 1 - sandy clay over $40 ; 2$ - pulverescent clay, less than 50

z26 1 - low from 68.954 to $70.080 ; 2$ - medium from 70.081 to $71.205 ; 3$ - high from 71.343 to 72.329 


\begin{tabular}{lll}
\hline Characteristic feature & Code & Intervals of values \\
\hline $\begin{array}{l}\text { Grain-size composition } \\
\text { of the clays, }\end{array}$ & $\mathrm{Z}_{27}$ & $1-$ low from 23.871 to 24.895; 2- medium from 25.896 to 27.920; 3 - high from 27.921 to 29.945 \\
pulverescent grain & & \\
content, mass \% & &
\end{tabular}

To the above mentioned characteristic features we add 4 compulsory features (zone, subzone, road district, supporting point). The compulsory features are applied to 3 zones only, since Western Siberian territory has been investigated partly. We pointed out 1 subzone and 1 road district in the 1 st zone, 2 subzones and 7 road districts - in the 2nd zone and 2 subzones and 3 road districts - in the 3rd zone.

Illustrating example of matrices $\mathrm{Q}^{\mathrm{e}}, \mathrm{R}^{\mathrm{e}}$ and $\mathrm{R}^{\prime}$ descriptions is given in Fig. 1. The matrices correspond to partial knowledge description. We use only a part of the characteristic features space and its values.

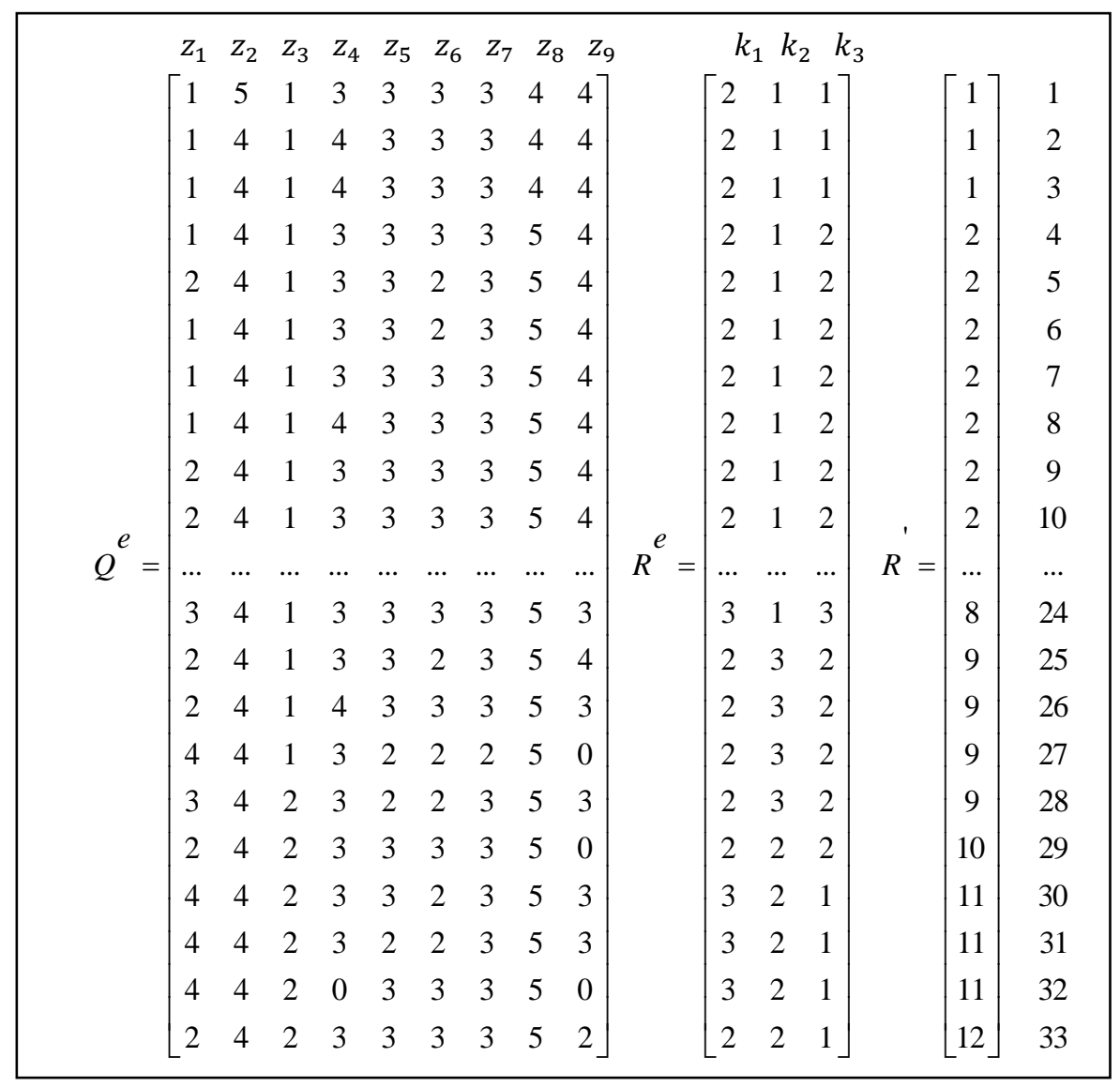

Fig. 1. Fragments of the extended matrices of description and distinguishing.

For the matrix model, filled in by the experts, the expert knowledge on the four zones, all the subzones and all the road districts are included. The fragments of description and distinguishing the matrices are represented in Fig. 2.

There are examples of usage of some visualization tools including cognitive graphics tools. The free-distributed open-street maps (OSM) [23] with information layer overlay for the presentation of common information are proposed. Information layer presents road regions with borders and some information about its. This information is a number of zone and subzone which are determined for road region. The proposed visualization tool is presented on Fig. 3.

In doing so note that for the mapping of decision-making results with usage of cognitive graphics tools we use 3-simplex for the zones representation and 2-simplex for subzones representation in case when the number of subzones equals 3 [24].

The information layer is denoted by number 1. It is a transparent layer over the map. The thin black lines separate the different road regions. The different color tones are used for labeling the different zones (red color tone is used for zone 2 , blue color tone is used for zone 3). Each color of the road region in every zone is unique color gradation from zone base color given from color transformation in the hue-saturation-bright palette (HSB palette). The wide black lines are used to separate the different zones. Hatching over road region shows subzone type. Only 3 hatching types are used and only 2 types from them presented on Fig. 3. Description for all used colors and hatching is presented in the legend (see Fig. 3) and it is denoted by number 2. There is a list of all used hatchings and presented subzones in the upper part of the legend. The list of all used zones and correlated road regions is in the bottom part of the legend. 
The information window for a road region is shown after click on a road region presentation. This window contains full information about a region. This information contains the road region name, 3 -simplex and 2-simplex as information about proximity to specific zone (left 3-simplex) and subzone (right 2-simplex). The OUI (road region) is displayed as the circle with a big radius. Objects of learning sample are displayed as circles with smaller radiuses. The distance from the object OUI to an edge is directly-proportional to proximity of the object to the pattern corresponding to the edge. Distances of an OUI to edges are displayed as color lines. Color of an OUI (or objects from a learning sample) is mapped to the pattern which belongs to the concrete object. Mathematical foundations of the visualization of these objects with use of n-simplex are given in [25,26].

\begin{tabular}{|c|c|c|c|c|c|c|c|c|c|c|c|c|c|c|c|c|}
\hline \multirow{22}{*}{$Q=$} & $Z_{1}$ & $Z_{2}$ & $z_{3}$ & $Z_{4}$ & $Z_{5}$ & $Z_{6}$ & $Z_{7}$ & $Z_{8}$ & $Z_{9}$ & \multirow{22}{*}{$R^{e}=$} & $k_{1}$ & $k_{2}$ & $k_{3}$ & & & \\
\hline & 2 & 4 & 2 & 4 & 3 & 3 & 2 & 5 & 47 & & 2 & 1 & & & 1 & 1 \\
\hline & 2 & 4 & 2 & 4 & 3 & 3 & 2 & 5 & 4 & & 2 & 1 & 1 & & 1 & 2 \\
\hline & 2 & 4 & 2 & 4 & 3 & 3 & 2 & 5 & 4 & & 2 & 1 & 1 & & 1 & 3 \\
\hline & 2 & 4 & 2 & 4 & 3 & 3 & 2 & 5 & 4 & & 2 & 1 & 2 & & 2 & 4 \\
\hline & 2 & 4 & 2 & 4 & 3 & 3 & 2 & 5 & 4 & & 2 & 1 & 2 & & 2 & 5 \\
\hline & 2 & 4 & 2 & 4 & 3 & 3 & 2 & 5 & 4 & & 2 & 1 & 2 & & 2 & 6 \\
\hline & 2 & 4 & 2 & 4 & 3 & 3 & 2 & 5 & 4 & & 2 & 1 & 2 & & 2 & 7 \\
\hline & 2 & 4 & 2 & 4 & 3 & 3 & 2 & 5 & 4 & & 2 & 1 & 2 & & 2 & 8 \\
\hline & 1 & 4 & 1 & 0 & 3 & 3 & 3 & 4 & 5 & & & 1 & 2 & & 2 & 9 \\
\hline & 1 & 4 & 1 & 0 & 3 & 3 & 3 & 4 & 5 & & 2 & 1 & 2 & , & 2 & 10 \\
\hline & $\ldots$ & $\ldots$ & $\ldots$ & $\ldots$ & $\ldots$ & $\ldots$ & $\ldots$ & $\ldots$ & $\ldots$ & & $\ldots$ & $\ldots$ & $\ldots$ & $R=$ & $\ldots$ & $\ldots$ \\
\hline & 4 & 4 & 4 & 2 & 2 & 2 & 2 & 6 & 2 & & 3 & 1 & 3 & & 8 & 207 \\
\hline & 4 & 4 & 4 & 2 & 2 & 2 & 2 & 6 & 2 & & 2 & 3 & 2 & & 9 & 208 \\
\hline & 4 & 4 & 4 & 2 & 2 & 2 & 2 & 6 & 2 & & & 3 & 2 & & 9 & 209 \\
\hline & 4 & 4 & 4 & 2 & 2 & 2 & 2 & 6 & 2 & & 2 & 3 & 2 & & 9 & 210 \\
\hline & 4 & 4 & 4 & 2 & 2 & 2 & 2 & 6 & 2 & & 2 & 3 & 2 & & 9 & 211 \\
\hline & 4 & 4 & 4 & 2 & 2 & 2 & 2 & 6 & 2 & & 2 & 2 & 2 & & 10 & 212 \\
\hline & 4 & 4 & 4 & 2 & 2 & 2 & 2 & 6 & 2 & & 3 & 2 & 1 & & 11 & 213 \\
\hline & 4 & 4 & 4 & 2 & 2 & 2 & 2 & 6 & 2 & & & 2 & 1 & & 11 & 214 \\
\hline & 4 & 4 & 4 & 2 & 2 & 2 & 2 & 6 & 2 & & 3 & 2 & 1 & & 11 & 215 \\
\hline & 4 & 4 & 4 & 2 & 2 & 2 & 2 & 6 & 2 & & 2 & 2 & $1]$ & & 12 & 216 \\
\hline
\end{tabular}

Fig. 2. Fragments of the matrices of description and distinguishing, filled in by highly qualified experts.

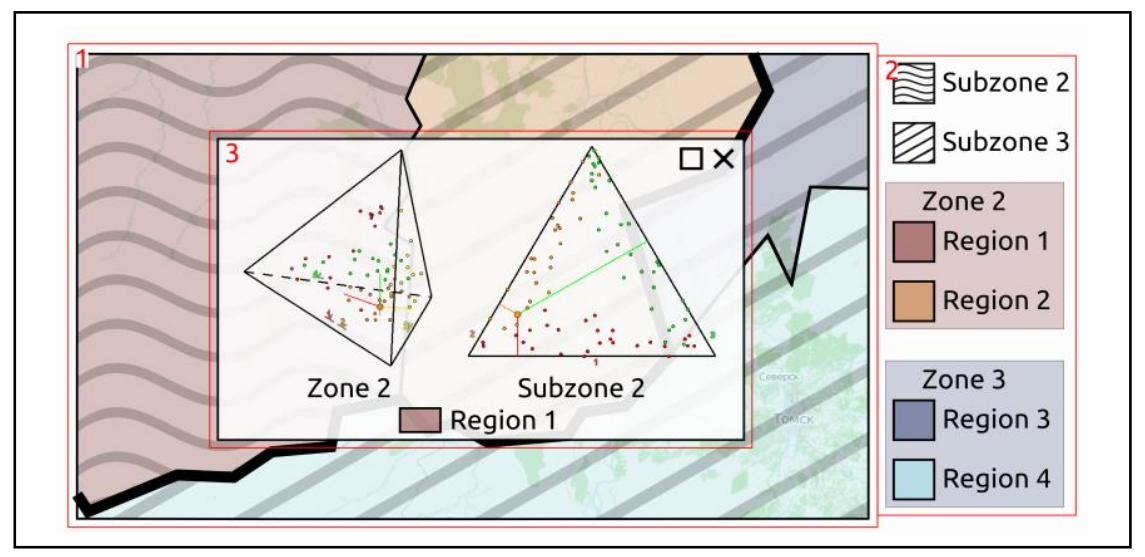

Fig. 3. Visualization tool for representation of the map with zoning results.

We revealed the different types of regularities on the basis of algorithms proposed by A. Yankovskaya and realized in IS RCZT. The revealed regularities allowed to reduce the features space from 27 to 11. That, in turn, has led to reduction of quantity of revealed feature values on $59 \%$.

We also verified the decisions-making using the generated supporting point descriptions proposed by A. Yankovskaya. The research results showed the IS RCZT development will lead to reduce significantly the expenditure and the cost of field and laboratory works on the territories under investigation. That, in its turn, will essentially reduce time expenses the specialists of road branch for the identification of zone, subzone and road district of the territory under investigation.

The proposed approach on road-climatic zoning of territories will allow to provide the required level of operational reliability of the highways. 


\section{Conclusion}

The analysis of domestic and foreign standards of designing and building of highways is given. The advisability of creation intelligent systems road-climatic zoning of territories is substantiated.

For the first time we proposed the complex matrix model of data and knowledge representation for road-climatic zoning. It has allowed to carry out structurization of the data and knowledge on the road-climatic zoning. Complex matrix model is represented by the 3 matrix models: the extended matrix model that includes the extended matrix of description and the matrix of distinguishing; the matrix of knowledge description and the matrix of distinguishing filled with highly qualified experts; the partial matrix model consisting of the extended matrix of description of the territories under study.

It is created a prototype of the intelligent system of road-climatic zoning. On the basis of extended matrix representation it is created data and knowledge base using the research results on natural and climatic conditions of Western Siberian regions. The base of date and knowledge was created highly qualified experts.

For the $1^{\text {st }}$ and the $2^{\text {nd }}$ matrix representations of data and knowledge are revealed and is eliminated at a finding of intersections of objects descriptions from different patterns.

Results of a research prototype approbation of road-climatic zoning of the territories intelligent system have shown as follows: reduction on $59 \%$ of necessary number of characteristic features for decision-making on reference of territory part under study to this or that zone, a subzone and road district. Application IS RCZT will decrease significantly the expenditure and cost on the field and laboratory research of the territories under study. That will also save the reduce time expenses of the road branch specialists.

The proposed approach on road-climatic zoning of the territories will allow to provide demanded level of operational reliability of again under construction and reconstructed highways and first of all in regions with the poorly developed network of highways.

\section{Acknowledgements}

The research was funded by RFBR grant (project No. 14-07-00673a and No. 16-07-0859a). The authors are grateful to V. Efimenko, Doctor of Science; S. Efimenko, Doctor of Science; M. Badina, Candidate of Science for the information on roadclimatic zoning of West Siberian regions; to V. Churilin, senior lecturer for the data and knowledge base fulfilling; to R. Ametov, Deputy director of the Information Technologies Center of the Tomsk State University of Architecture and Building and A. Yamshanov, Junior research fellow, assistant of the Tomsk State University of Control Systems and Radioelectronics for the IIS IMSLOG development and for revealing the regularities within the developed data and knowledge base on road climatic zoning; to S. Kitler, the executor of the project No 16-07-00859a for experiments conducting.

\section{References}

[1] Gavrilova TA, Kudryavcev DV, Muromcev DI. Knowledge Engineering. Models and methods. St.P.: Publishing company "Lan”, 2016; 324 p. (in Russian)

[2] Highways: SP 34.13330.2012. M.: Ministerstvo regional'nogo razvitiya RF, 2013; 106 p. (in Russian)

[3] Design of flexible pavement: ODN 218.046-01. M.: Informavtodor, 2001; 145 p. (in Russian)

[4] Code of Practice for Highway Routes of the People 's Republic of China: JTG D20-2006. People's Communications Press, 2006.

[5] Chao Li, Yu-lan Wang, Jin-liang Xu. Research on Geographic Information System of Natural Zoning for Highway. Applied Mechanics and Materials 2013; 353-356: 3502-3506.

[6] "Filing system" of physiographic units helps to resolve local design criteria. Highway Res. News 1973; 51: 42-60.

[7] Richlinien fur die Standartisierung des Oberbaues von Verkehrsfiuchen: RStO 01. Köln.: FGSV-Verlag, 2001.

[8] Groney D. The design and performance of road pavements. London: Transport and road research laboratory, $1977 ; 673$ p.

[9] Highways: SNiP RK 3.03-09-2006. Astana: Proektnaya akademiya "KAZGOR", 2014; 51 p. (in Russian)

[10] Highways. Flexible pavement. Design rules: TKP 45-3.03-112-2008. Minsk.: Ministroiarhitekturi, 2009 ; 86 p. (in Russian)

[11] Design. Highways: SNiP RK 32-01:2004. Bishkek: Goskomarhstroi pri Pravitel'stve Kirizskoi Respubliki, $2004 ; 85$ p. (in Russian)

[12] Efimenko SV, Efimenko VN, Afinogenov AO. The Outline of Road Building Climatic Zoning in Western Siberia. Vestnik TSUAB 2013; 4(1-3): 78-84.

[13] Efimenko SV, Badina MV. Road zoning of Western Siberia: monography. Tomsk: Publishing of TSUAB 2014; 244 p. (in Russian)

[14] Ushakov VV, Efimenko VN, Vishnevskiy AV. Road-climatic zoning of highway "Amur" Chita - Khabarovsk under the terms of the construction and operation. Highways 2007; 5: 77-79. (in Russian)

[15] Yarmolinskiy VA. Khabarovsk territory zoning in snow cleaning of roads. Vestnik TSUAB 2014; 5: 152-158. (in Russian)

[16] Yankovskaya AE, Gedike AI, Ametov RV, Bleikher AM. IMSLOG-2002 Software Tool for Supporting Information Technologies of Test Pattern Recognition. Pattern Recognition and Image Analysis 2003; 13(2): 243-246.

[17] Yankovskaya AE, Gedike AI, Ametov RV. Constraction of applied intellegent sistems on the base of software tool IMSLOG-2002. Vestnik TSU. Application 2002; 1(II): 185-190. (in Russian)

[18] Yankovskaya AE, Efimenko VN, Efimenko SV, Cherepanov DN. Application of matrix models for creation of intelligent information technology in sphere of the state and municipal management. Fuzzy systems and soft computing: Proceedings of $6^{\text {th }}$ Russian science-practical conference. St.P.: Politehknikaservis 2014; 2: 118-127. (in Russian)

[19] Yankovskaya A, Cherepanov D, Selivanikova O. Data and Knowledge Base on the Basis of the Expanded Matrix Model of Their Representation for the Intelligent System of Road-Climatic Zoning of Territories. IOP Conf. Series: Materials Science and Engineering 2016 ; $142: 012041$.

[20] Efimenko VN, Efimenko SV, Sukhorukov AV. Accounting for natural-climatic conditions in the design of roads in Western Siberia. Sciences in Cold and Arid Regions 2015; 7(4): 307-315.

[21] Efimenko SV. Territorial homogeneity of geographic complexes in design of automobile roads. Vestnik TSUAB 2015; 3: 226-236. (in Russian)

[22] Yankovskaya AE, Ametov RV. Architecture of intelligent system oriented on road-climatic zoning of territories. Proceedings of the Congress on intelligent systems and information technologies. Taganrog: Publishing UFU 2016; 1: 98-104. (in Russian) 
Image Processing, Geoinformation Technology and Information Security / A. Yankovskaya, A. Sukhorukov

[23] Yankovskaya A, Yamshanov A. Bases of intelligent system creation of decision making support on road-climatic zoning. Pattern Recognition and Information Processing (PRIP'2014): Proceedings of the 12 $2^{\text {th }}$ International Conference. Minsk: UIIP NASB 2014: $311-315$.

[24] Yankovskaya A, Yamshanov A. Family of 2-simplex cognitive tools and their application for decision-making and its justifications. Computer Science \& Information Technology (CS \& IT) 2016; 6(1): 63-76.

[25] Yankovskaya A, Krivdyuk N. Cognitive Graphics Tool Based on 3-Simplex for Decision-Making and Substantiation of Decisions in Intelligent System. Proceedings of the IASTED International Conference Technology for Education and Learning (TEL 2013). Marina del Rey, USA, 2013 : 463-469.

[26] Yankovskaya AE, Yamshanov AV, Krivdyuk NM. Application of Cognitive Graphics Tools in Intelligent Systems. IJEIT 2014; 3(7): 58-65. 